Saudi Journal of Medicine

Abbreviated Key Title: Saudi J Med ISSN 2518-3389 (Print) |ISSN 2518-3397 (Online)

\title{
Particulate Matters, (PM) 2.5, 1, and 10 Measurements in Lahore and Indication of Their Harmful Effects on the Ocular Epithelium
}

\author{
Shiraz Aslam ${ }^{1 *}$, Lamia Yusuf ${ }^{2}$, Zobiah Hafeez $^{3}$, Muhammad Akhlaq $^{4}$, Hina Sadaf ${ }^{5}$, Saba Iqbal ${ }^{6}$ \\ ${ }^{1}$ Professor ENT, Pak Red Crescent Medical College, Dina Nath, Kasur, Punjab, Pakistan \\ ${ }^{2}$ Associate Professor Gynaecology \& Obstetrics, Pak Red Crescent Medical College, Dina Nath, Kasur, Punjab, Pakistan \\ ${ }^{3}$ Senior Demonstrator Physiology, University College of Medicine \& Detansary, Lahore, Pakistan \\ ${ }^{4}$ Professor ENT, Pak Red Crescent Medical College, Dina Nath, Kasur, Punjab, Pakistan \\ ${ }^{5}$ Assistant Professor Physiology, Azra Naheed Medical College, Superior University, 17 KM Raiwind Rd, Kot Araian, Lahore, Punjab, Pakistan \\ ${ }^{6}$ Assistant Professor Medical Education, Pak Red Crescent Medical College, Dina Nath, Kasur, Punjab, Pakistan
}

DOI: $10.36348 /$ sjm.2020.v05i11.001

| Received: 21.10.2020 | Accepted: 05.11.2020 | Published: 11.11.2020

*Corresponding Author: Dr. Sheraz Aslam

\section{Abstract}

Introduction: This study stresses upon the importance of protecting the eyes from chemicals and particulate matter in the atmosphere of our cities and the possible harmful effects this can have on adults and the future generations. Objective: This study endeavors to point out the harmful chemicals and the presence of dangerous particulate matters in the air and the possibility of its effects on the ocular functioning. Study Design: This was a cross sectional study. Setting: This study was carried out in specific areas in Lahore, Pakistan. Time Duration: As it was a cross sectional study so the data was collected in a 12 hour period in various specific areas of Lahore. Method: A purpose built monitoring device was used to take pollutant readings at various sites in Lahore. Result: The levels of PM2.5, PM1 and PM10 were all above the WHO recommended standards in all areas in Lahore. The heaviest concentration was at Data Darbar which is incidentally most crowded area as well. Conclusion: There is heavy and constant exposure to the eyes of these particulate matters especially the fine, PM2.5 chemicals which are highly injurious to the eyes in addition to the lungs, heart and the central nervous system.

Keywords: Air Pollution, Dry Eye Syndromes, Environmental Pollution, Particulate Matter, PM2.5, PM1, PM10, pediatric conjunctivitis.

Copyright (C) 2020 The Author(s): This is an open-access article distributed under the terms of the Creative Commons Attribution 4.0 International License (CC BY-NC 4.0) which permits unrestricted use, distribution, and reproduction in any medium for non-commercial use provided the original author and source are credited.

\section{INTRODUCTION}

Pollution is a problem in every country of the world but the developing countries like Pakistan have more problems due to poor infrastructures and little will of the governments and the common people to take responsibility. The particulate matter concentrations in Pakistan are a serious hazard and a threat to future generations [1].

The particulate matters are a mixture of solids and liquid droplets. The PM2.5 is 2.5 micron in diameter but has lethal effects on the lungs, heart, Central nervous system and the eyes. The PM2.5 originates from burning of natural fuels such as coal or wood car exhaust emissions are major culprits and it is noted that the heavy trucks were the main source of pollution in Delhi [2].

Although, every human being is vulnerable to the ill effects of the particulate matters but the most under threat are the ones at extremes of ages like the very young and the elderly. People who have preexisting pulmonary conditions such as asthma and bronchitis and also cardiac problems are also in danger if exposed to these particulate matters for a long time. The W.H.O has issued guidelines regarding the acceptable levels of PM2.5 in the atmosphere. The acceptable level is a concentration of $25 \mu \mathrm{g} / \mathrm{m} 3$ in a 24 hours period. The environment protection agency of Australia has categorized the 'air quality' which corresponds to different concentrations of PM2.5 in the air. Anything above $60 \mu \mathrm{g} / \mathrm{m} 3$ in an hour of exposure is termed "very poor" and is the last and the worst category described [3].

Particulate matters which are larger like the PM10 are also in abundance in the atmosphere. These are 10 micrometers in size and are described as thec PM2.5 in terms of their concentration in micrograms per meter cube [4]. As they are larger in size, they are called 'coarse' particles as compared to the 'fine' particulates such as the PM2.5. The PM 10 originates from pollen, and again from un-burnt motor fuel and 
engine exhaust. These are released from industries as well [5].

In Pakistan, the so-called 'green belts' are a major source of PM10 as these are not adequately maintained and have no greenery on them and the only thing they present is dust, which they contribute to the surrounds in great numbers and are a big source of PM10 aprticles. Pm10 can also cause major pulmonary and cardiac ailments [6]. The recommended acceptable concentration in the air of these PM10 particles is $50 \mu \mathrm{g} / \mathrm{m} 3$ in a 24 hour period. According to the environmental protection agency's air quality guidelines, anything above $12 \mu \mathrm{g} / \mathrm{m} 3$ in one hour's exposure, warrants to be labeled as "very poor" quality of air [7].

In our country winters are more troublesome as indoor wood and kerosene oil are burnt for cooking and mostly within the confines of the dwellings which leads to a polluted atmosphere within the house and a severe health hazard to the occupants of the rooms [8].

\section{METHODOLOGY}

This was a cross sectional study where the data was collected at various randomly selected 16 different sites in Lahore. A new multi item pollution monitoring device (Life Basis DM 106 A) was used to measure the pollutant levels. The device was reset and recalibrated before taking readings from a new area. The device was left in the atmosphere where the reading measuring was going for 3 minutes for the pollutants to have a good chance to enter the device sensors. There was random selection of the areas to be monitored in Lahore and the selection of the sites was only convenience dependent. The readings were then entered into a table.

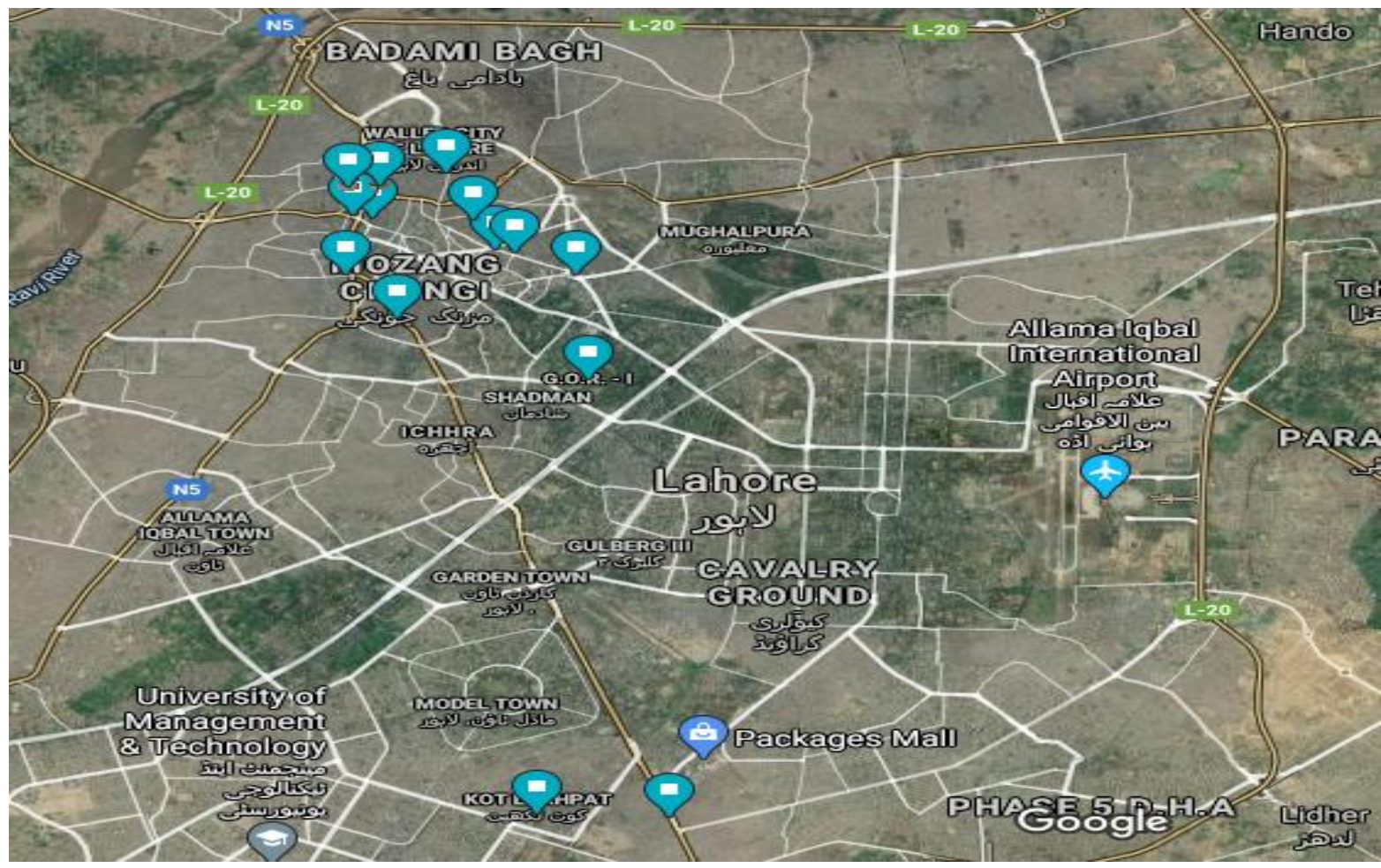

Picture-1: Selected areas in Lahore

https://www.google.co.uk/maps/@31.5335261,74.4090143,18482m/data=!3m1!1e3

\section{RESULTS}

The concentrations of the two important and injurious particulate matters (PM2.5 and PM10) were found to be more than the WHO acceptable levels in all areas of Lahore included in this study. The average PM 2.5 levels were $79.4 \mu \mathrm{g} / \mathrm{m} 3$. In comparison the WHO recommends a safe level of $25 \mu \mathrm{g} / \mathrm{m} 3$. The measured level is almost three times the safe level of PM2.5.
The highest level of PM2.5 was found in the Data Darbar area $(90 \mu \mathrm{g} / \mathrm{m} 3)$ and the second highest was at Gawal Mandi area $(85.5 \mu \mathrm{g} / \mathrm{m} 3)$. The average of the PM10 comes out to be $244 \mu \mathrm{g} / \mathrm{m} 3$, whereas the WHO recommendation is $50 \mu \mathrm{g} / \mathrm{m} 3[8,1]$. The measured amount being almost 5 times the safe limit described. Again the levels at Data Darbar and Lakshmi areas were found to be the highest at 330 and $340 \mu \mathrm{g} / \mathrm{m} 3$ respectively- 6 time the safe levels. 
Table-1: Measured various particulate matter concentrations in the atmosphere in Lahore

\begin{tabular}{|l|l|l|l|l|}
\hline S/No & Areas of Lahore & PM $\mathbf{2 . 5} \boldsymbol{\mu g} / \mathbf{m 3}$ & $\mathbf{P M ~ 1} \boldsymbol{\mu g} / \mathbf{m 3}$ & $\mathbf{P M ~ 1 0} \boldsymbol{\mu g} / \mathbf{m 3}$ \\
\hline 1 & Jail Road & 73 & 199 & 265 \\
\hline 2 & Ferozepur Road & 81 & 190 & 164 \\
\hline 3 & Lytton Road & 80 & 164 & 196 \\
\hline 4 & MAO College & 77 & 170 & 223 \\
\hline 5 & Kacheri & 77 & 160 & 200 \\
\hline 6 & G.C.U & 77 & 198 & 253 \\
\hline 7 & Data Darbar & 90 & 259 & 330 \\
\hline 8 & Bhati Gate & 80 & 200 & 268 \\
\hline 9 & Shahalami & 84 & 203 & 247 \\
\hline 10 & Bansanwala Bazar & 80 & 185 & 256 \\
\hline 11 & Gawalmandi & 85.5 & 175 & 232 \\
\hline 12 & Lakshmi & 80.3 & 263 & 340 \\
\hline 13 & Montgomery Road & 79 & 200 & 256 \\
\hline 14 & Shimla Pahari & 82 & 189 & 245 \\
\hline 15 & Davis Road & 84 & 182 & 223 \\
\hline 16 & G.O.R 1 & 61 & 155 & 207 \\
\hline
\end{tabular}

\section{DISCUSSION}

Particulate matters are present in a variable concentration in almost all countries of the world. They are more in the developing country where there are poor infrastructure and the need for daily basic sustenance of the family is the priority rather than regard for a clean environment $[9,10]$. In the developing world, the governments have little will or awareness and desire to endeavor to provide a clean and healthy environment to its citizens. If they do have the intention to do so it is usually obstructed by economic reasons or a lack of infrastructure $[11,12]$.

Particulate matter are normally categorized as 'coarse' particles which usually of $10 \mu \mathrm{m}$ in diameter and the other 'fine' particles which are $2.5 \mu \mathrm{m}$ in diameter and smaller. For visualization of the size involved, it is helpful to remember that the human hair is from 70 to $100 \mu \mathrm{m}$ in diameter whereas the dust particle that you can see against the light is about $10 \mu \mathrm{m}$ in diameter [7].

An extensive Chinese study has reviewed 29 different research articles originating from China between 2009 and 2016 into the sources of PM2.5. It is evident from other international studies as well that the main sources of PM 2.5 inside and outside of the house are in the form of urban dust, coal dust, automobile exhaust emissions, secondary organic carbon and nitrates, smoke from biomass burning construction dust [5].

An interesting fact that these researchers highlighted was the fact that even inside the house the concentration of the Pm2.5 was not too different from what it was outside at that particular moment of time. Therefore, the indoor/outdoor ratio (I/O) was up to 0.867. This they found in a dwelling of "normal airtightness and without HVAC- filters (Heating, Ventilating, and Air Conditioning) installed". The pollution would rise inside the dwelling as the ambient particulate matter concentration rose. Hence, the recommendation, for properly fitted windows and doors in buildings [12].

There are certain groups of people who are particularly vulnerable to the adverse effects of these particles. These are in the extremes of ages like the elderly and the very young. However, people who have respiratory, cardiovascular problems and diabetes are also vulnerable. This is not to say that ordinary adults are not are exposed to unusually large concentrations of these particles as seen in the readings at The Data Darbar in the present study. The W.H.O. has issued guidelines regarding the allowable concentrations of these particles in the atmosphere. If their concentration rises, the incidence of serious health affects rise as well. The level which is recommended is $25 \mu \mathrm{g} / \mathrm{m} 3$ in the 24 hour mean for the PM2.5 particulates and is $50 \mu \mathrm{g} / \mathrm{m} 3$ in the 24-hour mean for the Pm 10 particulates $[13,7]$.

Glancing down the measurement readings in the table in this study, it is clear how polluted our environment is especially in the Data Darbar area (PM2.5 $90 \mu \mathrm{g} / \mathrm{m} 3$ ).No area in Lahore at the particular time of measurement was within the WHO allowable limits. Although the GOR-1 area $(61 \mu \mathrm{g} / \mathrm{m} 3)$ is relatively better by $32 \%$ as compared to the Data Darbar area, it is still below the WHO recommendation of the PM2.5 concentration of $25 \mu \mathrm{g} / \mathrm{m} 3$.

People who are constantly exposed to such particulate matters such as the policemen on duty, who have to stay put at a spot for hours amongst heavy traffic, dust, fumes, and smoke will understandably be liable to more eye infections. In addition to this uniformed personnel, ordinary vendors, and shopkeepers without protective doors to their shops will be exposed as well. Unfortunately, school children's eyes will be exposed to all the smoke and fumes daily 
basis especially when they have to tread to and from school. Corneal wound healing might be impaired by PM2.5 effects in terms of inhibiting cell migration. Infections may set in under these circumstances and damage the eye further [9].

The damage occurring to the ocular epithelium may be due to the 'autophagy' triggered by the PM2.5 particulate matters resulting in corneal cytotoxicity [11]. Dry eye syndrome is a major problem in Asia probably due to greater pollution problems. So that the Asia Dry Eye Society (ADES) has issued a clear definition of what constitutes dry eyes-"Dry eye is a multifactorial disease characterized by unstable tear film causing a variety of symptoms and/or visual impairment, potentially accompanied by ocular surface damage [14].”

Anyone who has dry eye syndrome will have dry itchy eyes with a possible burning sensation and this may give slight impairment in vision or photosensitivity as well. The major problem with dry eyes is due to the interruption or absence of the tear meniscus at the lower lid margin giving dryness and a scratchy feeling in the eyes. Tear osmolarity is changed as well [15]. People living in Asia and also the elderly seem to be more affected by dry eye syndrome [16].

Particulate matters such as the PM2.5 and PM10 can cause irritation not only in the nose and throat but in the eyes as well when it comes into direct contact with the ocular surface epithelium. A person who suffers from dry eyes already will be more susceptible to their effects. It was reported by researchers that ocular exposure to these particulate matters in the mice produced an increased level of TNF- $\alpha$, NF- $\kappa$ B p65 (phospho S536), and NF- $\kappa$ B in the cornea. These surface changes are the same as seen in the dry eyes syndrome $[17,7]$.

Researcher have attempted to answer the reason why there is an increase in IL-5 and IL-10 levels when the eye surface is exposed to high concentrations of the particulate matters (PM2.5) in the air. It is suggested that this could be due to the fact that the eye epithelium is responding immunologically to the particulate onslaught resulting in the release of cytokines or just that the ocular surface was adjusting to the persistently high levels of pollutants in the air [16, 2]. Some other researchers have stressed also that the corneal epithelium is damaged due to the fact that the pollution interacts with the exposed surface and elicits an immune response resulting in the release of interleukin 8 with higher oxidative stress created due to an imbalance of free radicals and antioxidants in the body, which can lead to cell and tissue damage [10].

The Chinese researchers have reported a strong association between the concentrations of air pollutants like the particulate matters both the fine and the coarse ones and also dioxides of sulfur and nitrogen with the dry eye disease [11]. Researchers in Spain have found out that climate does affect the integrity of the ocular surface and tear stability as well. This could be due to the warm climes in certain parts of Spain $[13,18]$.

Experiments in mice have revealed how the particulate matters can damage the delicate structure and functioning of the eye. The researchers were able to show that a direct allergic conjunctivitis reaction was induced by exposure of the eye to the pollution. This resulted in an eosinophil Infiltration the upper and lower palpebral conjunctivas and meibomian glands. It was also noted that there were changes in the goblet cell concentrations in the upper and the lower conjunctivas [19]. Exposure to the air pollutants will lead to immediate irritation to the mucous membranes of the nose and also has the potential to cause allergic conjunctivitis. Experimental exposure to these particulate matters to mice resulted in an allergic reaction which included eosinophil infiltration in the conjunctivas of the upper and the lower palpebra and the meibomian glands of both the palpebra as well [20].

A distinct entity called the "unspecific conjunctivitis of unknown origin" (UCUO) may be due to exposure to these pollutants. It is suggested that children suffer from this in greater numbers and there is a further association between this (UCUO) and heavily polluted areas [21, 22]. In other experiments on mice, the eyes were seen to be affected directly and resulted in thinning of the epithelial layer of the central area of the cornea and a decrease in the density of the goblet cells. This was seen as a result of exposure to a heavy concentration of particulate matter in the air [17]. PM2.5 causing DNA damage in the corneal epithelial cells was suggested by another study from China but the question, if this was due to long or short term exposure, was left unanswered [9]. Particulate matters are known to cause serious health problems leading to slight irritation to the nose, eyes, and throat to more threatening ailments like asthma, bronchitis, and heart problems from arrhythmias to cardiac arrest. These pollutants are more deadly to children. It is estimated that there was a "statistically significant $14 \%$ increase in all-cause mortality for a $10-\mu \mathrm{g} / \mathrm{m} 3$ annual increase in PM2.5" [19]. The impact of exposure to particulate matter of 2.5 microns in diameter is serious enough to lead to human premature mortality and is reported to be the sixth largest risk factor for worldwide premature deaths attributable to PM2.5 exposure [23]. Thus, major causes of death (cardiac, pulmonary, or cardiovascular) have been associated with prolonged exposure to particulate matters [24].

International Agency for Research on Cancer (IARC) has labeled particulate matters (PM) in the atmosphere which cause pollution as 'Group I carcinogen' which is done when there is 'sufficient evidence of carcinogenicity' related to the chemical or 
material under question. Consequently, an increased risk for lung cancer-related deaths $(15 \%)$ was found to be attributable to these particulate matter exposures [12].

\section{RECOMMENDATIONS}

Tree Plantation can play a vital role in combating climate change, which affects our city, Improve air quality in Lahore, especially in thick polluted areas, it has worsened in the last few years and the sources of air pollution ranged from thermal power plants, brick kilns, vehicles exhaust, several industrial plants, cutting the trees, diesel generator sets, and waste burning. No single source or sector alone can reduce the current levels of PM10 and PM2.5 concentrations. The US AQI deems a PM2.5 concentration of 60 micrograms per cubic meter in the air as "unhealthy." For the current levels of PM pollution in the city, the health impacts analysis estimates 200,00 premature deaths and 135,000 asthma attacks per year. The local government of Lahore needs to develop an action plan on urgent bases encompassing multiple sources and include technological, institutional, and behavioral interventions

Conflict of Interest: Authors declare no conflict of interest.

Payment/services info: All authors have declared that no financial support was received from any organization for the submitted work.

Financial support: All authors have declared that they have no financial Support from any organization.

\section{REFERENCES}

1. Colbeck, I., Nasir, Z. A., \& Ali, Z. (2010). The state of ambient air quality in Pakistan-a review. Environmental Science and Pollution Research, 17(1), 49-63.

2. Guttikunda, S. K., \& Goel, R. (2013). Health impacts of particulate pollution in a megacityDelhi, India. Environmental Development, 6, 8-20.

3. World Health Organization. (2018). Burden of disease from ambient air pollution for 2016 Description of method v5 May 2018. World Heal Organ. 2017(May):6. Available from: http://www.who.int/airpollution/data/AAP_BoD_ methods_Apr2018_final.pdf?ua $=1$

4. Fu, Q., Lyu, D., Zhang, L., Qin, Z., Tang, Q., Yin, H., ... \& Yao, K. (2017). Airborne particulate matter (PM2. 5) triggers autophagy in human corneal epithelial cell line. Environmental Pollution, 227, 314-322.

5. Lin, Y., Zou, J., Yang, W., \& Li, C. Q. (2018). A review of recent advances in research on PM2. 5 in China. International journal of environmental research and public health, 15(3), 438.

6. Dobaradaran, S., Geravandi, S., Goudarzi, G., Idani, E., Salmanzadeh, S., Soltani, F., ... \&
Mohammadi, M. J. (2016). Determination of cardiovascular and respiratory diseases caused by PM10 exposure in Bushehr, 2013. Journal of Mazandaran university of medical sciences, 26(139), 42-52.

7. Tan, G., Li, J., Yang, Q., Wu, A., Qu, D. Y., Wang, Y., ... \& Shao, Y. (2018). Air pollutant particulate matter 2.5 induces dry eye syndrome in mice. Scientific reports, 8(1), 1-13.

8. Riaz, R., \& Hamid, K. (2018). Existing smog in Lahore, Pakistan: an alarming public health concern. Cureus, 10(1):1-3.

9. Cui, Y. H., Hu, Z. X., Gao, Z. X., Song, X. L., Feng, Q. Y., Yang, G., ... \& Pan, H. W. (2018). Airborne particulate matter impairs corneal epithelial cells migration via disturbing FAK/RhoA signaling pathway and cytoskeleton organization. Nanotoxicology, 12(4), 312-324.

10. Yoon, S., Han, S., Jeon, K. J., \& Kwon, S. (2018). Effects of collected road dusts on cell viability, inflammatory response, and oxidative stress in cultured human corneal epithelial cells. Toxicology letters, 284, 152-160.

11. Mo, Z., Fu, Q., Lyu, D., Zhang, L., Qin, Z., Tang, Q., ... \& Lou, X. (2019). Impacts of air pollution on dry eye disease among residents in Hangzhou, China: a case-crossover study. Environmental Pollution, 246, 183-189.

12. Hamra, G. B., Guha, N., Cohen, A., Laden, F., Raaschou-Nielsen, O., Samet, J. M., ... \& Loomis, D. (2014). Outdoor particulate matter exposure and lung cancer: a systematic review and metaanalysis. Environmental health perspectives. 122(9):906-11.

13. Tesón, M., López-Miguel, A., Neves, H., Calonge, M., González-García, M. J., \& González-Méijome, J. M. (2015). Influence of climate on clinical diagnostic dry eye tests: pilot study. Optometry and Vision Science, 92(9), e284-e289.

14. Gupta, P. D., \& Muthukumar, A. (2018). Minor to Chronic Eye Disorders Due to Environmental Pollution: A Review. J Ocul Infect Infamm, 2(2): 1-5.

15. Tsubota, K., Yokoi, N., Shimazaki, J., Watanabe, H., Dogru, M., Yamada, M., ... \& Yoon, K. C. (2017). New perspectives on dry eye definition and diagnosis: a consensus report by the Asia Dry Eye Society. The ocular surface, 15(1), 65-76.

16. Schaumberg, D. A., Sullivan, D. A., Buring, J. E., \& Dana, M. R. (2003). Prevalence of dry eye syndrome among US women. American journal of ophthalmology, 136(2), 318-326.

17. Sheng, Z., Wang, S., Zhang, X., Li, X., Li, B., \& Zhang, Z. (2019). Long-Term Exposure to LowDose Lead Induced Deterioration in Bone Microstructure of Male Mice. Biological Trace Element Research, 1-8.

18. Yu, D., Deng, Q., Wang, J., Chang, X., Wang, S., Yang, R., ... \& Yu, J. (2019). Air pollutants are associated with dry eye disease in urban 
ophthalmic outpatients: a prevalence study in China. Journal of translational medicine, 17(1), 46.

19. Miyazaki, D., Fukagawa, K., Fukushima, A., Fujishima, H., Uchio, E., Ebihara, N., ... \& Okamoto, S. (2019). Air pollution significantly associated with severe ocular allergic inflammatory diseases. Scientific Reports, 9(1), 19.

20. Tang, Y., Chang, H., Chiang, C., Lai, C., Hsu, M., \& Han, H. (2019). Anatomy and Pathology / Oncology by Continuous Exposure to Particulate Matter. 2(5): 4-12.

21. Varu, D. M., Rhee, M. K., Akpek, E. K., Amescua, G., Farid, M., Garcia-Ferrer, F. J., ... \& Dunn, S. P. (2019). Conjunctivitis Preferred Practice Pattern®. Ophthalmology, 126(1), P94.
22. Li, Z., Bian, X., Yin, J., Zhang, X., \& Mu, G. (2016). The effect of air pollution on the occurrence of nonspecific conjunctivitis. Journal of Ophthalmology, 2016:10-3.

23. Lepeule, J., Laden, F., Dockery, D., \& Schwartz, J. (2012). Chronic exposure to fine particles and mortality: an extended follow-up of the Harvard Six Cities study from 1974 to 2009. Environmental health perspectives, 120(7), 965-970.

24. Wang, X., Chen, M., Zhong, M., Hu, Z., Qiu, L., Rajagopalan, S., ... \& Ying, Z. (2017). Exposure to concentrated ambient PM2. 5 shortens lifespan and induces inflammation-associated signaling and oxidative stress in drosophila. Toxicological Sciences, 156(1), 199-207. 